\title{
We Shall Fight: Speaker-Exclusive $W e$ as a Grammatical Metaphor
}

\author{
Francesca Santulli \\ DSLCC, Università Ca’ Foscari \\ Dorsoduro, 30123 Venezia, Italy \\ E-mail: francesca.santulli@unive.it
}

Received: April 29, 2020

Accepted: June 8, 2020

Published: July 7, 2020

doi:10.5296/ijl.v12i4.16931

URL: https://doi.org/10.5296/ijl.v12i4.16931

\begin{abstract}
The first person plural pronoun cannot be considered as an expression of pluralization of the first. Its semantic boundaries are defined in context, and this inherent vagueness that can be pragmatically exploited for communicative purposes. Beyond the frequently investigated opposition between (addressee-) inclusive vs exclusive forms, this paper explores non-prototypical uses of the first person plural pronoun, focusing on the conflicts that arise when it is used in contexts that semantically exclude the speaker. Speaker-exclusive forms can occur in different situations, ranging from interpersonal exchanges to public discourse. The paper investigates their different semantic implications, highlighting their common traits as well as their crucial peculiarities. Both the review of the literature and the analysis of actual examples bring forth the different values and functions of various speaker-exclusive occurrences of the first person plural. A more systematic categorization of the forms can be obtained adopting a metaphorical interpretation, which on the one hand emphasises their common denominator (i.e. speaker-exclusiveness) and, on the other, sheds light on their varying communicative potential.
\end{abstract}

Keywords: First person plural, Speaker-exclusive we, Grammatical metaphor, Rhetorical-we

That's a small step for me, but a giant leap for us

Neil Armstrong, as imagined by Nathan Salmon

\section{Introduction}

The words that Neil Armstrong could have pronounced when setting his foot on the Moon show one of the possible contradictions stemming from some occurrences of the first person 
plural pronoun (Note 1). Though it is a mere reformulation of the actual historical utterance (Note 2), the sentence contains an opposition between small and giant that is semantically conflictual, as the same person (i.e. the speaking subject, referred to by $I$ and included in we) is in both contrasting positions (for me vs for $u s$ ). The conflict can be solved if the first person plural is intended in its non-prototypical meaning of 'people in general', i.e. mankind. In this paper, I will explore the main functions and values of the first person plural pronoun, focusing on the conflicts that arise when it is used in contexts that semantically exclude the speaker, and suggesting that a metaphorical interpretation can contribute to a more systematic categorization of the various forms and shed light on their varying communicative potential.

The first person plural pronoun cannot be considered as an expression of pluralization of the first, for both logico-semantic and morphological reasons (Benveniste 1966). Its meaning denotes "the self plus at least one other" and can extend to include humanity as a whole (Urban 1987; Wilson 1990); differently put, it indicates the "speaker and a variable" (Nunberg 1993). Therefore, the semantic boundaries of we are defined in context with the possibility of leaving them blurred, a vagueness that can be pragmatically exploited for communicative purposes. Research primarily focused on the opposition between (addressee-) inclusive vs exclusive forms, which is also morphologically marked in some languages (Benveniste 1966). More recently, different and more subtle distinctions have been considered, including less frequent and non-prototypical uses of the pronoun (Helmbrecht 2015).

This paper explores the possibility of excluding the speaker from the semantic reference of the first person plural. This can occur in different contexts and for different purposes, which will be examined on the basis of both previous studies and personal observation. After a review of the most common interpretations of the first person plural, I will examine the uses that semantically exclude the speaker (speaker-exclusive: Wilson 1990), apparently contradicting its very definition. Actually, the exclusion of the speaker can be obtained with different means. The interpretation of the pronoun can be shifted towards the addressee, thus generating a hearer dominant form (De Cock 2011, 2016), which was already described by Jespersen (1933:148) as paternal-we, and more recently as condescending we (Quirk et al. 1985), also called nursery-we or pseudo-inclusive (Helmbrecht 2002, 2015). Furthermore, the speaker may use the first person plural to express a close relationship with a third party (we = they), or create an in-group which actually s/he does not belong to (we = they/you-group). Starting from the seminal interpretation of the first person plural put forth by Benveniste, I will examine its non-prototypical uses as they are described in current English dictionaries and grammatical descriptions, with special attention for speaker-exclusive forms. Speaker-exclusive uses will be described in different contexts, with a view to bringing forth their different functions. In order to emphasise their common traits as well as their crucial peculiarities, I will suggest that speaker-exclusive forms can be interpreted as a grammatical metaphor. In the light of Prandi's interpretation of metaphorical expressions (Prandi 2004), I will consider how the semantic conflict is managed, and distinguish between regressive, catachresis interpretation and projective, creative use. 


\section{Benveniste}

In his 1946 essay devoted to Structure des relations de personne dans le verb, Benveniste singles out a corrélation de personnalité, opposing first and second person (je/tu) to the non-person ( $\mathrm{il}$ ), and a corrélation de subjectivité, opposing first to second person (je to $t u$ ). The complex nature of pronominal forms is discussed with constant reference to actual forms occurring in a high number of typologically different languages, and considering at the same time grammatical descriptions and denominations. In Benveniste's work, the main focus is on singular forms, which he examines for their pragmatic value and their capacity of linking the énoncé to the situation of enunciation (Note 3). As for plural forms, the special character of pronouns is recognised by Benveniste also on the basis of morphological observations. In most languages, different words are used for je and nous (and for $t u$ and vous) and the rules for plural formation in nominal paradigms are not applied, with very rare exceptions (Benveniste mentions Eskimo, only for the first person). The historical datum is in tune with the special character of the relation between singular and plural pronominal forms, which is particularly complicated for the first person:

Le passage du singulier au pluriel n'implique pas une simple pluralisation. [...] 'nous' est, non pas une multiplication d'objets identiques, mais une jonction entre 'je' e le 'non-je', quel que soit le contenu de ce 'non-je'. Cette jonction forme une totalité nouvelle et d'un type tout particulier, où les composantes ne s'équivalent pas : dans 'nous', c'est toujours 'je' que prédomine puis-qu'il n'y a de 'nous' qu'à partir de 'je', et ce 'je' s'assujettit l'élément 'non-je' de par sa qualité transcendante. La présence du 'je' est constitutive du 'nous' (Benveniste 1966 [1946] :233).

Two aspects emerging from Benveniste's work deserve comment. On the one hand, the composite nature of we, which can be filled with two different semantic interpretations (inclusive or moi + vous, and exclusive or moi + eux), is morphologically evident in numerous languages spoken in different parts of the world, which have separate forms for the two functions. On the other hand, the pivotal role of je is emphasised, to the point that nous without moi is presented as ontologically impossible. Benveniste does not consider the hearer-oriented interpretations I have mentioned above, but he suggests that in the inclusive form the emphasis is laid on toi, vous, as opposed to lui, eux, while in the exclusive form moi is brought to the forefront as opposed to toi, vous. This hints to a different level of involvement of the speaker, which cannot however lead to total disappearance of moi as the constitutive element of nous. Rather, in the special conditions of pluralization characterizing pronominal forms, the predominance of $j e$ can be very strong, to the point that the plural can be used with a singular reference. The subject is dilated to cover a blurred area, giving rise to two opposite but non-contradictory interpretations: the amplified and solemn je typical of pluralis majestatis on the one hand, and on the other the damped je manifesting a larger and diluted identity, typical of authorship. (Note 4)

\section{From Benveniste to Discourse Analysis}

In more recent times, pronominal forms have been frequently analysed in the pragmatic perspective, from both the cognitive and the communicative point of view. The first person 
plural, however, has attracted less attention when compared with the first person singular or with both forms of the second. In the wake of Brown/Gilman's (1960) focus on the interpersonal role of pronominal choices, functional to expressing power vs solidarity, numerous studies have privileged a sociolinguistic approach, and examined how alternative forms occur and characterize the position of speakers in a given context, establishing conversational roles and social hierarchies (Silverstein 1976, 2003). On the other hand, in a more genuinely pragmatic perspective, research has investigated the different forms of self-presentation, frequently drawing inspiration from Goffman's approach and the notions of framing and footing (Goffman 1974, 1981). This line of research is primarily interested in the creation of perspectives in discourse (Ensink and Sauer 2003), which heavily relies on the representation of the self as a personal subject or the various impersonal forms. The ancillary role of the first person plural is confirmed in a recent volume dedicated to the pragmatics of personal pronouns (Gardelle and Sorlin, 2015a). The book includes a wide choice of interesting papers dealing with different contextual uses across genres and functions, but no chapter is focused on the first person plural, though some of its non-prototypical occurrences are mentioned in the Introduction, with reference to social deixis ('nurse-we' and 'royal-we') and media uses (Gardelle and Sorlin, 2015b: 13-14).

Actually, the use of first person plural forms (both we/us and our/ours) has been mainly investigated in the context of discourse studies, with a special focus on media and political communication (van Dijk 1991; Fairclough 1989, 1995; Maitland and Wilson 1987; Wilson 1990; Zupnik 1994; Wodak 1989, 1997; Duszak 2002; Davies 2013; Casañ-Pitarch 2016; Sarlin 2017; Yang 2017; White 2017, and many others). The starting point is always the assumption that we cannot be interpreted as the plural form of $I$ (as already claimed by Jespersen 1924 and Benveniste 1966), apart from some special situations "when several persons are co-author of the same speech act" (Daniel 2005: 10). This 'choral usage' is however limited to very few pragmatic situations (e.g. more authors writing a paper together), with a marginal and almost negligible role. Moreover, it can be noted that, even in the context of choral usage, it is impossible to pluralize $I$, as each participant to the speech act speaks for her/himself, and a homogeneous multiplication of a first person identity is inherently impossible. The plural form has to be interpreted in terms of addition of heterogeneous terms, a junction (in Benveniste's terms) of the speaking subject with someone else. Urban (1986) represented the semantics of $w e$ as a series of inclusive circles, progressively expanding from the centre (we $=\mathrm{I}+$ one other) to the outer periphery (we = I + the humanity). The interesting point here is the vagueness of meaning, as the boundaries of we-reference are fully blurred. Moreover, in many languages there is one single form of first person plural pronoun, and therefore it is not possible to distinguish between inclusive we (which includes in the syntactic function both speaker and receiver/s) and exclusive we (which marks the absence of the receiver/s in the syntactic function) (Prieto 1977). This opposition has been analysed in a more comprehensive perspective (including the possibility of applying it also to the second person), with reference to a wide choice of typologically different languages (Filimova 2005; Lim 2018; Lovestrand 2018). 


\section{Mll Macrothink}

International Journal of Linguistics

ISSN 1948-5425

2020, Vol. 12, No. 4

In media and political contexts, it is possible to exploit this vagueness and ambiguity of pronominal reference for persuasive aims. The use of pronouns is therefore functional to the creation of discursive identities (Han and Chen 2019; Skorczynska 2020), of in- and out-groups (we as opposed to them), as is common practice in journalism (Fowler 1991; Allan 2004; Davies 2013) and in the discourse of politicians (Maas 1984; Wilson 1990; Pennycook 1994; De Fina 1995; Postoutenko 2009; Moberg and Eriksson 2013; Roitman 2014; Yu and Wu 2017; Alinezhad and Nemati 2019, and many others). In discourse studies, however, Benveniste's comprehensive interpretation is usually neglected, and there is only generic reference to the work of the French linguist, if any. The most frequently mentioned point is the opposition inclusive vs exclusive we, which is generally taken for granted and not connected with other aspects of the pragmatic interpretation of the first person plural pronoun. Similarly, special uses such as pluralis majestatis, pluralis modestiae or hearer-dominant we are rarely considered relevant to this area of language research.

\section{Language Descriptions}

A more systematic approach can be found in current language descriptions, dictionaries in the first place (Note 5). Rastall (2003) revised definitions of we in a wide choice of dictionaries and grammar books, to offer a synthetic picture of the different types of reference and their interpretation. The review is still valid, as more recent versions of the sources consulted have introduced no significant innovation. Though with different levels of detail and exemplification, dictionaries agree on the classification of the uses of the pronoun: we to refer to the speaker and one or more other people is mentioned as the first (prototypical) use, usually extended with the addition of a defining word or phrase aiming to create a group, as in the following examples:

(1) we psychologists (OED),

(2) we teachers (Merriam-Webster).

General reference is also mentioned, emphasising its impersonal use:

(3) we need to take care of our bodies (Collins),

(4) we should eat as varied and well-balanced diet as possible (Merriam-Webster).

Further forms are: we = I, sometimes distinguishing 'royal we' (or pluralis majestatis) and 'editorial we' (or pluralis modestiae); we = you, which corresponds to the hearer dominant use mentioned above.

Dictionaries do not explicitly mention the (addressee-) inclusive vs exclusive opposition, though Merriam-Webster gives a rather subtle analysis of the basic meaning:

I and the rest of the group that includes me: I and you: you and I and another or others: I and another or others not including you (Merriam-Webster).

However, dictionaries obviously focus on more codified interpretations of the we-reference (we $=\mathrm{I}$, we $=$ you $)$. 
The speaker-exclusive use of we is described in the OED as follows:

Used confidentially or humorously to mean the person or persons addressed, with whose interests the speaker thus identifies himself or herself (esp. by a doctor in friendly or cheering address to a patient); also used mockingly or reproachfully by a parent, intimate friend, etc. (OED)

The first recorded occurrence dates back to 1702:

Vanbrugh, False Friend: "Well, old Acquaintance, we are going to be married then?".

The definition given by the OED is the most detailed. Merriam-Webster simply indicates that it is "used condescendingly to refer to the person being addressed", giving the following example:

(5) How are we today?

Collins (British version) mentions "a tone of persuasiveness, condescension, or sarcasm", and specifies (American version) that it is "used in direct address as in encouraging or admonishing an invalid, a child, etc.". The absence of the speaker is not explicitly mentioned.

A rather different approach characterizes grammar description. Quirk et al. (1985), still one of the most influential and comprehensive scientific grammars of English, identify a series of special uses of we: they distinguish "authorial" from "editorial" use, the former being characterized by inclusiveness (the speaker and his/her addressees), the latter used as a substitute for $I$ to obtain an impersonal style; they also mention "royal" and "generic" (people in general) we, as well as "third person" use, which is very similar to the condescending/sarcastic use (we = you, which is not mentioned), but referred to a third person, as in:

(6) we are in a bad mood today,

said by a secretary to someone else, referring to the boss. All these uses are also identified in the dictionaries examined above. Quirk et al. (1985) also single out a "rhetorical" use of we, as in:

(7) in the XIX Century, we ignored the poor.

In this case, the speaker includes her/himself in a category, which s/he actually does not belong to. Semantically speaking, it is an out-group, which the speaker ideally joins, possibly drawing her/his addressees into it, and thus generating a new, more comprehensive identity. Rastall (2003: 52) notes that a similar feeling of association seems to be involved in the rhetoric of the American Constitution: We the people is the expression of a collective feeling, and when modern Americans identify with the values of their Founding Fathers, they become part of a wider group extending across centuries. This special use of we is significantly described as rhetorical, as it has persuasive and metaphorical implications. Since it is hardly possible to give it a codified meaning (as in the cases we = you), it is quite obviously ignored in lexical descriptions, though it is a far more interesting case of speaker-exclusiveness. 


\section{Speaker-Exclusive Forms as a Non-Prototypical Use of We}

In the scientific literature, the context-based interpretation we $=$ you, regularly mentioned in dictionaries and grammatical descriptions, is usually included among non-prototypical pronominal usage. A typology (including both a cross-linguistic and a diachronic discussion) is presented by Helmbrecht (2015) in a paper published in a special issue of the Journal of Pragmatics edited by Lotte Hogeweg and Helen de Hoop. Not differently from the miscellaneous book mentioned above and other similar initiatives (Note 6), the volume is primarily focused on the second person, although nursery-we is offered as first example in the editorial (Hogeweg and de Hoop 2015). Helmbrecht himself includes in his typology all persons, aiming to give a comprehensive picture of non-prototypical uses. These are characterized by a shift in the semantic category, by an increase in pragmatic meaning, and by context-based restrictions (Helmbrecht 2015: 178). Actually, we $=$ you is treated as a prototypical example of non-prototypical uses, as the author mentions it in the abstract with reference to doctor-patient dialogues, exactly as in the editorial. In the discussion, however, it is not given special emphasis.

As for the first person plural, apart from the impersonal use and pluralis majestatis and modestiae, Helmbrecht singles out three further non-prototypical uses of we displaying different characteristics, but sharing a common trait, i.e. speaker-exclusiveness. He mentions (p. 182-183):

a) $1 \mathrm{pl}=3 \mathrm{pl}$, or we $=$ they, as used by supporters of a soccer club when saying:

(8) we won the game last night.

On the basis of his own experience, the author considers this use common in German, but emphasises that this may not be the case in French (he reports p.c.). It is definitely common in Italian, and frequently mentioned in the literature in English. Quite obviously, it implies a strong identification with an existing group (the soccer club) that is semantically distinct from the speaker, but is pragmatically represented in wider terms so that it includes the speaker (supporter). Using this non-prototypical reference, the supporter emphasises her/his sense of belonging to the club, which is constructed as a collective entity where there is no boundary separating actual players from mere supporters.

b) $1 \mathrm{pl}=2 \operatorname{sing}$, or we $=$ you (sing.), nursery-we, or, more technically, pseudo-inclusive. This denomination emphasizes two aspects: on the one hand, this use creates solidarity between $I$ and you typical of inclusive forms; on the other, this unity is only apparent, as the speaker is actually excluded from the pronominal reference. Apart from the usual examples taken from doctor-patient interaction, Helmbrecht mentions another communicative situation, which he has personally observed, namely the interaction between vendor and customer, when, after having shown two different products, the vendor asks:

(9) which one do we buy?

According to the author, while the doctor-we, though characterized by the strong commitment of the doctor, may turn out to be offensive for the patient due to the perception of authority in 
the doctor's words, the latter is not considered patronizing, as the vendor is felt to express proximity to the customer. A similar use of we occurs also in Italian (personal observation), but it may perceived as impolite, implying a sort of intrusion of the vendor into the personal space of the customer, who may feel 'besieged' for marketing reasons (personal inquiry).

c) $1 \mathrm{pl}=2 \mathrm{pl}$, or we $=$ you ( $\mathrm{pl}$.), as used by teachers addressing their students:

(10) we have learnt.../ we have finished our essay.

This use emphasises their commitment and involvement in the learning process of the students. It shares with the previous a similar asymmetrical structure of the interpersonal relation, based on a form of power/authority, combined with a strong emphatic attitude on behalf of the speaker, and is not always kept separate from the previous (s. Quirk et al.: 350).

However, the similarity among the three cases is not noticed by Helmbrecht. Further examples of speaker-exclusiveness are mentioned in the literature, mainly within the framework of hearer-dominant interpretations of we-reference. Barbara De Cock has extensively discussed this aspect, starting from a distinction between physical persons (speaker and hearer) and discursive roles (addresser and addressee) (De Cock 2011), which expands on Goffman' animator/author/principal model (1981). Contrary to the prototypical interpretation $($ speaker $=$ addresser, hearer $=$ addressee $)$, the referential vagueness of the first person plural allows other associations. In inclusive-we, for instance, the hearer is associated to the speaker as addresser. Moreover, the addresser-addressee complex conceptualization can better be represented as a continuum (Bazzanella 2009), in which the shift towards the addressee/hearer in special contexts (and with some constraints) conceptualizes the involvement of the addresser and her/his interest for the physical hearer (De Cock 2011: 2763-64). In a study also relying on corpus linguistic tools, De Cock (2011) tries a comparative review of the English and Spanish usage, aiming to single out textual and contextual features that promote hearer-dominance, which however turn out to be difficult to classify. In this area, a corpus-based approach is particularly difficult, for the limited availability of data concerning medical contexts (Note 7). Moreover, as there are no morphological traits associated with the different uses, automated retrieval of the forms is impossible. On the other hand, examples of hearer-oriented we can be found in fictional texts, ranging from narrative to TV series, which "are particularly interesting since authors choose them in order to create a certain narrative setting, thereby revealing their perceived interactional effect" (De Cock 2016: 364). In fact, historical examples given in the OED include a series of occurrences in fiction.

Another context in which hearer-oriented we occurs is the waiter-client interaction, as in:

(11) What are we having today?

De Cock (2016: 369) reports this possibility in Spanish, a language in which the first person plural can be used by a waiter with both habitual and new clients, without triggering impolite reading by the addressee. The situation seems different in Italian: Bazzanella (2002: 248) suggests that the use of the first person plural with new clients is usually perceived as impolite. The condescending-we seems justified in this context only if it occurs in a situation 
of acquaintance, where it contributes to creating a more personal relationship. The waiter-we does occur in English, though it may be perceived as unusual, or even incorrect. On the Merriam-Webster website, there is a section where users can indicate the reason why they have looked up a certain lemma in the dictionary. Among the comments concerning we, the following is worth mentioning:

(12) to find out if the restaurant servers are correct whey [sic!] say 'what are WE having today'. (Note 8)

This comment confirms the existence of this use in English, and also reveals that the addressee perceives something unusual, possibly incorrect (i.e. impolite) in the waiter's request.

Neither Helmbrecht nor De Cock explicitly comment on another crucial context for hearer-dominant we, namely the parent-child interaction, though the former mentions "other care-takers" who may use pseudo-inclusive-we to emphasise their involvement or commitment (Helmbrecht, 2015: 183), and the latter quotes an example originally given by Brown and Levinson (1987:118):

(13) Oh, dear, we've lost our little ball, haven't we, Johnny?

which apparently reproduces an adult-child interaction (De Cock 2011: 2766). The parental use is usually mentioned in dictionaries and grammar books (Jespersen [1933] used the denomination "paternal we"), and examples can be found in the literature. In Italian (personal observation), this use of the first person plural is common in mother-baby interactions, when the mother describes the actions and behaviour of her baby. In some cases the inclusion of the speaker is semantically possible:

(14) abbiamo fatto una pappa buonissima ('we had a very nice snack') (Note 9).

As the mother contributed in some way to the performance of the action, preparing and giving the food. In other cases, however, the speaker is semantically excluded, as in:

(15) abbiamo fatto una bella nanna ('we had a nice nap').

In these cases the action has been performed exclusively by the baby, and the mother seems to verbalize the comment on behalf of her baby, who is still unable to speak. Given the predominance of mothers as care-givers in early infancy in Italy, these forms more rarely occur in fathers' speech.

Utterances as the ones mentioned above are perceived as extremely empathic, as if they aimed to preserve the special mother-baby connection during pregnancy and immediately after delivery.

\section{Speaker-Exclusive as a Separate Category?}

To sum up, speaker-exclusive uses of the first person plural pronoun can be broadly classified into three main groups. 


\section{Mll Macrothink}

International Journal of Linguistics

ISSN 1948-5425

2020, Vol. 12, No. 4

The first one includes all the interpretations of we as you (singular), which can occur in various contexts, the most frequently mentioned being the doctor-patient, adult-child, waiter-client, and vendor-client relation. All these contexts seem to share a form of asymmetry, be it based on power/authority (doctor, parents, teacher) or on the offering of a service (waiter, vendor). The implications of this usage vary from condescendence to coaxing, but seem to include also empathy on behalf of the speaker. Occasionally, this form can be perceived as inappropriate, for different reasons. On the one hand, it is felt to emphasize the asymmetry in the relation (doctor/(old) patient), on the other, it is perceived as intruding or aiming to create an apparent closeness that actually does not exist (waiter to new client, vendor). There are also occurrences that emphasise an ironic component.

In the second group we can include the use of we = they, referring to a pre-existing and well-recognisable entity (supporter-soccer club), and the use of we $=$ you (plural) also referring to an easily identifiable group (teacher-class).

Finally, there are the 'rhetorical' uses of we, when the speaker aims to create a group which cannot semantically include her/him, but which s/he wants to be part of. This is the least codified use, which lends itself to different interpretations and can be conveniently exploited to obtain a persuasive effect.

It is evident that the three groups have different forms and functions, but they share the paradoxical exclusion of the speaker from a form that inherently includes her/him. This is a special circumstance, which justifies the attempt to find a common denominator for their interpretation. I suggest that they can all be interpreted as the result of a metaphorical conflict, which is differently managed and solved. To explore this possibility I shall refer to Prandi's theory of metaphor (Prandi 2004: 369-404).

\subsection{Transfer, Conflict, and Metaphor}

It is extremely difficult to give a clear and comprehensive definition of metaphor, as its domain includes profoundly different entities. A minimal definition "identifies in the first instance the largest common denominator shared by any kind of metaphor" (Prandi 2004: 388-389), and considers a metaphor as the transfer of a concept into an alien domain. This very general definition includes all different interpretations of metaphor: this is an advantage, but it is also its limit, since it only considers the initial transfer that triggers a conflict, but says nothing about the following processes. Prandi recalls de Vinsauf's metaphor of a metaphor as a sheep feeding in rure alieno. The point is that, when the sheep has jumped the fence, different things can happen, which cannot be known in advance. Plainly put, when a concept is transferred into an alien domain, different forms of interaction can occur, giving rise to an open range of possible conflicts and consequent possibilities of solving them.

Within this general framework, which actually includes a continuum of possibilities that can change in time and across different contexts, Prandi tries to single out the most important alternatives. The main distinction is between consistent and conflicting metaphors. When the transferred concept adapts to the new domain, the elements of meaning alien to the new context are suppressed, and conflict is blocked. The wings of a building have nothing to do with feathers or flying, and this trope can be better described as a lexical catachresis, which 
simply expresses a concept using an alien word, and is therefore a form of regressive, consistent transfer. A catachresis can lead to a 'dead metaphor'. On the other hand, when a metaphor is created to shape a new concept, the struggle for consistency is a progressive and creative process. The conflict is not avoided, rather actively created to force a new interpretation of reality. This is the case, for example, of Kuhn's metaphor of 'scientific revolution', which he introduced to conceptualize the paradigm changes in the evolution of science (Kuhn 1962). Halfway between catachresis and individual creations, there are shared metaphorical concepts, which are regressive but cannot be considered dead metaphors. They are grounded in conventional but productive schemes of thought, they do not adapt the transferred concept to the alien domain, but are integrated in our way of thinking, as when we interpret time in space terms, or money as a fluid entity.

The advantage of Prandi's interpretation of metaphor is that, in the dimension of the alternative between regressive and progressive analogy, all forms of metaphor can be put at some point along a continuum, which spans from lexical catachresis to ontological conflicts that "defy the essential properties of beings, which lie at the basis of consistency" (Ibid.: 393). In evaluative terms, while consistent metaphors are similar to other consistent concepts and independent of specific linguistic structures, an inconsistent metaphor is a pure semantic structure that is created thanks to the power of words. "Inconsistent metaphors are probes launched beyond the borders of consistent thought, to explore a conceptual territory that is the exclusive domain of both metaphor and linguistic structuring" (Ibid.: 396). In this respect, they are the prototype of metaphorical transfer.

\section{Metaphorical Uses of We}

In the light of Prandi's minimal definition of metaphor, the use of speaker-exclusive we can be interpreted as originating from a conceptual transfer. A pronoun semantically including the speaker is moved into a pragmatic context where reference to the speaker has to be excluded, and a conflict arises. The transfer concerns the anaphoric structure of the text, and therefore the consequent metaphorical conflict can be assigned to the domain of grammar. This does not imply automatic identification with Halliday's categorization of Grammatical Metaphor, which was introduced on the basis of the ideational and interpersonal metafunctions (Halliday 1985, Martin 1992, Simon-Vandenbergen et al. 2003). Within that line of thought, the metaphorical use of a pronoun should rather be classified as pertaining mainly to the textual metafunction, which in the original Grammatical Metaphor theory was only considered for the textual implications of metaphoric shifts (Halliday and Matthiessen 1999). (Note 10) Besides and beyond the systemic-functional perspective, I am now interested in discussing the different effects of a metaphorical transfer concerning pronominal reference. To this purpose, I will apply Prandi's scheme, and its three main categories, to the metaphorical uses of the first person plural pronoun.

In the first group, the regressive adaptation of the transferred concept entails total elimination of the semantic traits conflicting with the new domain. We no longer includes $I$, and is therefore interpreted as you. In this respect, the phenomenon is very similar to a lexical catachresis. The lexicographic organization of the meanings of we is perfectly consistent with 
this interpretation, as we $=$ you is explicitly identified as a sub-category with its own definition, possibly including additional contextual considerations and examples - exactly as dictionaries identify among the (secondary) meanings of wing the one referring to a wing-shaped part of a building.

This is a highly codified speaker-exclusive use, mostly occurring in a limited number of well-recognisable contexts. The metaphorical conflict is solved thanks to an interpretation that restores semantic coherence, as the addressee does not expect the speaker to actually include her/himself into the pronominal reference and accepts that the pronoun we stands for you. This is clearly confirmed in conversational contexts, starting from the most frequently quoted doctor-patient exchange. The question "how do we feel today?" is normally answered using the first person pronoun (I feel....). The following example reproduces a mother-child interaction:

(16) M.: su, ora prendiamo la medicina ('well, now we take the medicine')

Ch.: no, non la voglio ('no, I don't want it')

The child reacts consistently with the we = you interpretation. Something similar could happen in reported speech. Let's suppose that the child reports to his/her father:

(17) Ch. (to father): la mamma ha detto che devo prendere la medicina, ma io non la voglio ('mum said I have to take the medicine, but I don't want it').

In reported speech, the metaphor would be abandoned to turn to a consistent use of the pronouns, thus confirming that the semantic value of the trope had been correctly understood. Moreover, a deontic component would be introduced, thus revealing the condescending function of the pronominal choice.

The correct semantic interpretation does not exclude per se a negative judgement as to the acceptability of the metaphor. In other, more marginal situations where the hearer dominant form occurs, the addressee has no doubts in producing a correct semantic interpretation, though there can be perplexities concerning its correctness or politeness (waiter, vendor). In this respect, there may be remarkable differences across different languages and cultures.

In the second group, which includes shared metaphorical concepts positioned in-between regressive and projective analogy, the conflict triggered by the use of we not including $I$ is solved thanks to common interpretation of everyday experience. In this case, we does not necessarily mean you, but it refers to a pre-existing entity, which belongs to shared knowledge and is therefore easily recognisable. The teacher-we and the supporter-we are good examples of this metaphorical interpretation. They differ in relation to addressee-clusivity, as the former is inclusive and the latter can be both inclusive (if the supporter addresses another supporter of the same club) and exclusive (if this is not the case). Yet both forms semantically exclude the speaker and refer to an external group (the class/the team), which the speaker metaphorically joints. The reasons for this metaphorical choice on behalf of the speaker are different but share some common traits, as the teacher mainly 
expresses proximity, empathy and involvement in the learning process, while the supporter expresses his/her total identification with the team.

The group of projective and creative metaphors is the least codified, yet the most interesting from the point of view of their discursive interpretation and exploitation. It includes uses of we that, while not including the speaker, refer to new entities, which are actually created by the speaker, who metaphorically includes her/himself into them. Though semantically excluded from the reference, the speaker, as creator of the we-group, plays an active role, and the conflict stemming from her/his absence from the group is solved thanks to the power of her/his metaphorical demiurgisches Werkzeug (Weinrich 1963). Considering that this is the prototypical example of metaphorical transfer, the denomination 'rhetorical-we' sounds appropriate.

However, as metaphors are not subject to a dichotomy-based classification, but can be better interpreted along a continuum ranging from merely regressive to authentically progressive analogy, the rhetoric power of speaker-exclusive we is subject to dramatic variation. I will now examine a few examples, starting from (7).

In (7), the impossibility for the speaker to perform the action stems from a time constraint: a person speaking in the XXI century cannot be considered responsible for the behaviour of those you lived in the XIX. The easiest possibility to solve the semantic conflict is to activate the generic interpretation of we, i.e. we = mankind. In this example, however, this is not possible. The speaker is actually creating a group, whose boundaries are rather blurred. It includes people living in the XIX century, though not all of them, as it is opposed to 'the poor [of that time]'. Contrastively, it may include 'the XIX century rich' or, in a wider perspective, 'the powerful', those who should have taken care of the poor, but neglected them. Using the metaphor, the speaker indicates that s/he wants to be part of that group, implicitly suggesting that s/he does not belong to 'the poor'. In other words, the speaker is the contemporary counterpart of those who, in the XIX century, neglected the poor. However, the new time perspective makes it possible for the her/him to judge the consequences of the actions performed in the past, and therefore to take an evaluative stance. The speaker-exclusive pronoun is an expression of solidarity with the members of the created group, but it includes feelings of regret or even reproach for neglecting the poor. The position of the speaker in relation to the addressees is rather neutral, as there are no hints to indicate whether they should be included or not (though this may depend on the fact that the example is given with little contextualization).

The exclusion of $I$ from we due to time constraints is in fact rather common, but can be differently exploited in discourse. The following example is taken from a speech by Margaret Thatcher (March 1983, also quoted in Maitland and Wilson 1987):

(18) We shall fight for our freedom in time of peace as fiercely as we have fought in time of war.

Mrs Thatcher is evidently echoing Churchill's famous wartime speech, which I will analyse later. Here, I will not discuss who the first occurrence of we refers to, as this goes beyond the 
problem of speaker-exclusiveness. Mrs Thatcher is both semantically and pragmatically included in the group of fighters for freedom - be they the Conservatives, the British, or the Western world - but she did not fight at wartime. The second occurrence of the pronoun is speaker-exclusive, yet it is functional to creating (or, rather, evoking) a historical entity, the group of those who fought for freedom during the war. In this perspective, the British (or the Allies) come to the forefront, and this interpretation sheds new light on the first occurrence of the pronoun, which cannot be referred to the Conservatives, or Mrs Thatcher's Government, only. The metaphorical conflict is generated to lead to the identification of those who fought at war, and won it, with those who intend to fight at the present time.

As shown by the latter example, in political discourse speaker-exclusive we can be very skilfully exploited to manipulate the audience with a persuasive aim. I will conclude my analysis discussing a very famous example of speaker-exclusiveness, repeatedly occurring in one of the Churchill's most famous wartime speeches, we shall fight.

\subsection{Winston Churchill's We Shall Fight}

In a speech delivered on June $4^{\text {th }} 1940$ before Parliament, Churchill (who had been appointed as Prime Minister a few weeks earlier) commented on the defeat of the Allies and the Dunkirk evacuation, managing to transform a "military disaster" into a deliverance that, though not having "the attributes of victory" had "a victory inside" (Note 11). In the last part of the speech, Churchill fully exploited the power of inclusive-we, in a series of forms that, in a strictly semantic perspective, were evidently speaker-exclusive - most of them being we shall fight. The power of this expression is confirmed by the fact that the speech itself is referred to as the "we shall fight" speech.

In his ample dissertation on the use of personal pronouns in politics, Wilson (1990) mentioned this form as a good example of pragmatic exploitation of (speaker-) exclusiveness:

When Churchill says, 'we shall fight on the beaches, we shall fight on the landing grounds', the 'we' here does not include Churchill himself, in that he was by this time an old man and would hardly be enlisted to fight; and further, in the event of an invasion Churchill and other key members of the Government were to be air lifted out of the country. In this case the meaning of the form has been manipulated in context, something which is a pragmatic concern (Wilson 1990: 47).

In Wilson's analysis, the evident conflict between semantics and pragmatics is the starting point for a distinction between sociolinguistic variation (one form chosen as opposed to another) and pragmatic choice (one form used "in order to indicate (implicate) a somewhat different meaning" [Ibid.]). However, the question of speaker-exclusiveness is not further discussed in relation to Churchill's utterance. Actually, though highly interesting for its systematic effort of analysing the pragmatic aspects of political communication, also in relation to pronominal choices, Wilson's (1990: 48-50) classification of inclusive vs exclusive forms is rather confusing, as the author does not always make a clear distinction between speaker- vs addressee-clusivity. Urban's (1986) model of progressively distancing uses of we is considered inadequate to explain the classical medical example, where the 
speaking subject is not included (Note 12), but the ontological inconsistency of a we excluding $I$ is not even mentioned. In this respect, I believe that a metaphorical interpretation can better show how the semantics-pragmatics conflict is generated, and how linguistic choices contribute to creating a new reality, enhancing meanings that are rhetorically functional to the process of persuasion.

A preliminary examination of the actual use of we in the speech is necessary. A few occurrences of we are deployed through the speech, with different implications. Some of them are clearly addressee-exclusive (Churchill refers to himself and his government), e.g.:

(19) only 30 unwounded survivors were brought off by the Navy, and we do not know the fate of their comrades;

Some can be better interpreted as inclusive, e.g.:

(20) I do not feel that any reason now exists why we should not form our own opinions upon this pitiful episode, or remain basically ambiguous, e.g.:

(21) we must be very careful not to assign to this deliverance the attributes of a victory;

(22) we have had a large number of wounded come home safely to this country.

There is also an evidently speaker-exclusive occurrence:

(23) $[\ldots]$ the three corps forming the First French Army, who were still farther from the coast than we were.

Actually, the shift between (addressee-) exclusion vs inclusion is artfully exploited. A series of exclusive we, referring to the action of the Government (military planning, policy against the so-called fifth column, etc.), is in fact preceded and followed by evidently inclusive forms, namely:

(24) we have for the time being in this Island incomparably more powerful military forces than we have ever had at any moment in this war or the last;

(25) I would observe that there has never been a period in all these long centuries of which we boast when an absolute guarantee against invasion, still less against serious raids, could have been given to our people.

Thanks to this strategic deployment of undoubtedly inclusive forms, the exclusiveness of the other occurrences is weakened, and an ambiguous interpretation is fostered. Thus, those who are actually not involved in the actions of the Government (and possibly do not approve them) imperceptibly become part of the process as co-performers.

The most relevant, and metaphorical, exploitation of the first person plural comes however in the final part of the speech. It follows an interesting occurrence, which initially seems explicitly addressee-exclusive (reference to the Government), but is then expanded to include the Parliament and the nation as a whole: 
(1) At any rate, that is what we are going to try to do. That is the resolve of His Majesty's Government-every man of them. That is the will of Parliament and the nation.

Then comes the pressing series of we shall:

(2) We shall not flag or fail

We shall go to the end

We shall fight in France

We shall fight on the seas and oceans

We shall fight with growing confidence and growing strength in the air

We shall defend our Island, whatever the cost may be

We shall fight on the beaches

We shall fight on the landing grounds

We shall fight in the fields and in the streets

We shall fight in the hills

We shall never surrender.

It starts and ends with negative expressions, which enclose the anaphoric sequence dominated by the repetition of the verb fight. The crucial verb is anticipated by an alliteration with the [f] sound (flag or fail); its seven occurrences are followed by local indications (in France, on the seas, on the beaches, etc., in one case also with expression of manner [with growing confidence]), while the series is interrupted by another crucial verb, defend, which makes the goal of the fight explicit. The phonic effect is particularly strong, as the pronoun is repeated in the initial position, as required by the English syntax. Moreover, Churchill uses the future form, which entails the repetition of the auxiliary, thus reinforcing the auditory effect of the anaphora. I will not discuss the functions of shall, which are not limited to a mere expression of futurity; suffice to say that a deontic component can be easily perceived, if only as a reminiscence of Biblical use.

Observing this well-constructed sequence, it is easy to forget that in most of the represented actions the speaker is not included. Churchill cannot fight. It is not possible to eliminate the inconsistency through a shift in the meaning of fight, since the indications of place unequivocally indicate that Churchill is not proposing a metaphorical interpretation of the verb. The actual use of the pronoun is metaphorical. Nor can the conflict be solved by a simple substitution of you for we, which would block the metaphorical process and generate a catachresis. This is no stereotyped use, we is not referring to a pre-existing analogical entity. It is actually creating it. The group represented by we is to be generated thanks to the conflict itself. The addressees are therefore included in this fighting entity, starting from the institutional audience (i.e. the members of Parliament) to include those who are physically present in the hall (be they journalists or individual citizens) and all those who receive the 
speech through media channels. Thus, the whole British nation is called to action, as confirmed by a final inclusive occurrence of the first person plural ('our Empire').

Not surprisingly, the powerful verbal machine generated a wave of approval, rooted into a strong national identity, and a movement of identification with a collective entity, which was to perform the required action. In Joe Wright's movie Darkest Hour, the last words uttered by Viscount Halifax pay due tribute to Churchill's rhetorical effort: "He mobilized the English language and sent it into battle".

\section{Concluding Remarks}

The first person plural pronoun, whose basic value and functions were clearly identified by Benveniste and consistently integrated in his theory of pronominal use, has been less frequently investigated than the second person, both singular and plural. Though its non-prototypical uses have attracted the attention of a few researchers, who have explored hearer dominant contexts beside well-established and classified forms of pluralis majestatis and modestiae, the first person plural has been mainly analysed for its discursive implications, with reference to the possibility of including or excluding the audience from pronominal reference. In languages that do not have separate morphological forms for different functions, the vagueness and semantic ambiguities that inherently characterize we obviously lend themselves to exploitation for manipulative and persuasive aims. This is especially frequent in certain domains, as news and political discourse.

In this paper, I have focused on a wide range of special uses of we that share a common and crucial trait, namely the exclusion of the speaker from the pronominal reference, aiming to organize them into a consistent and possibly comprehensive classification. Therefore, I have examined existing definitions, denominations and examples that are given both in the scientific literature and in current language descriptions (i.e. dictionaries and grammar books). I have shown that, although it seems possible to single out sub-groups of similar uses within the larger speaker-exclusive category, single occurrences may have different nuances of meaning and/or pragmatic implications, both in the perspective of politeness and for their ideological and persuasive value.

In order to develop a classification that includes all speaker-exclusive forms, emphasizing at the same time their most relevant differences, and leaving furthermore the possibility of putting single occurrences along a continuum of variation, I propose to interpret speaker-exclusiveness as a metaphorical transfer, which gives rise to a conceptual conflict that can be solved with different means and processes. Namely, the conflict between the prototypical meaning of the pronoun (which includes the speaker) and its use in a context where the speaker must be excluded on the basis of evident contextual information triggers the quest for a solution.

In a first group of occurrences, including a series of contexts where the use is highly stereotyped, the interpretation of we as you blocks the metaphorical process, and gives rise to a catachresis. The doctor-patient interaction is perhaps the most often quoted example of this type, which includes also adult-child (or mother-baby), waiter-client, vendor-client and, on 
some occasions, informal/friendly exchanges. The automatized we $=$ you reading does not exclude the possibility of perceiving inappropriateness or impoliteness in the use of the form.

In a second group, the conflict is solved attributing to the speaker strong involvement or even total identification with a pre-existing and well-defined entity, as for example a class (in the case of a teacher) or a soccer club (in the case of a supporter). These metaphors are rooted into shared knowledge.

Finally, the third group includes those forms of transfer generating a conflict that cannot be solved with mere standardized re-interpretation nor through regressive analogy. In these cases, the conflict is progressively exploited to create a new entity, which the speaker joins, possibly including her/his addressees in the process. These metaphors are particularly effective and can lead to continually renewable interpretations. Not surprisingly, they occur in political discourse and are exploited to obtain consensus and persuasion, a typical and famous example being Churchill's "we shall fight" metaphor.

\section{References}

Allan, S. (2004). News Culture. Maidenhead: Open University Press.

Bazzanella, C. (2002). The significance of context in comprehension: the 'we case'. Foundations of Science, 7, 239-254.

Benveniste, É. (1966). Structure des relations de personne dans le verb. In Problèmes de linguistique générale (pp. 225-236). Paris: Gallimard.

Brown, P., \& Levinson, S. (1987). Politeness: Some Universals in Language Usage. Cambridge: Cambridge University Press.

Brown, R., \& Gilman, A. (1960). The pronouns of power and solidarity. In Th. A. Sebeok (Ed.), Style in Language (pp. 253-276). Massachusetts: MIT Press.

Casañ-Pitarch, R. (2016). Case study on banks' webpages: The use of personal pronouns. International Journal of Language Studies, 10(4), 37-58.

Daniel, M. (2005). Two ways of pronominal number categorization. In M. Haspelmath, et al. (Eds.), World Atlas of Language Structures. Oxford: Oxford University Press.

Davies, M. (2013). Opposition and Ideology in News Discourse. London: Bloomsbury.

De Cock, B. (2011). Why we can be you: The use of 1st person plural forms with hearer reference in English and Spanish. Journal of Pragmatics, 43, 2762-2775.

De Cock, B. (2016). Register, genre and referential ambiguity of personal pronouns: A cross-linguistic analysis. Pragmatics, 26(3), 361-378.

De Cock, B., \& Kluge, B. (2016). On the referential ambiguity of personal pronouns and its pragmatic consequences. Pragmatics, 26(3), 351-360.

De Fina, A. (1995). Pronominal choice, identity and solidarity in political discourse. Text-Interdisciplinary Journal for the Study of Discourse, 15(3), 379-410. 
Duszak, A. (Ed.) (2002). Us and Others. Social Identities across Languages, Discourses and Cultures. Amsterdam/Philadelphia: John Benjamins.

Ensink, T., \& Sauer, C. (Eds.) (2003). Framing and Perspectivising in Discourse. Amsterdam/Philadelphia: John Benjamins.

Fairclough, N. (1989). Language and Power. London: Longman.

Fairclough, N. (1995). Media Discourse. London: Edward Arnold.

Filimova, E. (2005). Clusivity, Typology and Case Studies of the Inclusive-Exclusive Distinction. Amsterdam/Philadelphia: John Benjamins.

Fowler, R. (1991). Language in the News: Discourse and Ideology in the Press. London: Routledge.

Gardelle, L., \& Sorlin, S. (2015a). The Pragmatics of Personal Pronouns. Amsterdam/Philadelphia: John Benjamins.

Gardelle, L., \& Sorlin, S. (2015b). Personal pronouns. An exposition. In L. Gardelle, \& S. Sorlin (Eds.), The Pragmatics of Personal Pronouns (pp. 1-23). Amsterdam/Philadelphia: John Benjamins.

Goffman, E. (1974). Frame Analysis: An Essay on the Organization of Experience. New York: Harper \& Row.

Goffman, E. (1981). Forms of Talk. Philadelphia: University of Pennsylvania Press.

Halinezhad, H., \& Nemati, M. (2019). Divulging Power of Words. Personal Pronouns and Speech Acts in Political Speeches. The Journal of Teaching English for Specific and Academic Purposes, 7(2), 211-224.

Halliday, M. A. K. (1985). An Introduction to Functional Grammar. London: Edward Arnold.

Halliday, M. A. K., \& Matthiessen, Ch. (1999). Constructing Experience through Meaning. A Language-Based Approach to Cognition. London: Cassell.

Han, Y., \& Chen, J. (2019). "We Were Not at School Today": First-Person Pronouns and Discursive Construction of Identities by Emerging Middle-Class Chinese Parents. Chinese Journal of Applied Linguistics, 42(3), 285-306.

Helmbrecht, J. (2002). Grammar and function of we. In A. Duszak (Ed.), Us and Others. Social Identities across Languages, Discourses and Cultures (pp. 31-49). Amsterdam/Philadelphia: John Benjamins.

Helmbrecht, J. (2015). A typology of non-prototypical uses of personal pronouns: synchrony and diachrony. Journal of Pragmatics, 88, 176-189.

Hogeweg, L., \& de Hoop, H. (2015). Editorial. Introduction: The flexibility of pronoun reference in context. Journal of Pragmatics, 88, 133-136. 
Jespersen, O. (1924). The Philosophy of Grammar. London: George Allen \& Unvin.

Jespersen, O. (1933). Essentials of English Grammar. London: George Allen \& Unvin.

Kuhn, T. S. (1962). The Structure of Scientific Revolutions. Chicago \& London: University of Chicago Press.

Lim, D. (2018). Pragmatic effects of number and person in Korean pronominal system: Three uses of first person plural wuli. Lingua, 204, 1-15.

Lovestrand, J. (2018). Plural addressee marker and grammaticalization in Barayin. Brill's Journal of Afroasiatic Languages and Linguistics, 10(1), 52-82.

Maas, U. (1984). Als der Geist der Gemeinschaft eine Sprache fand. Sprache im Nationalsozialismus. Versuch einer historischen Argumentationsanalyse. Opladen: Westdeutscher Verlag.

Maitland, K., \& Wilson, J. (1987). Pronominal selection and ideological conflict. Journal of Pragmatics, 11(4), 495-512.

Martin, J. R. (1992). English Text: System and Structure. Amsterdam/Philadelphia: John Benjamins.

Moberg, U., \& Eriksson, G. (2013). Managing ideological differences in joint political press conferences. A study of the strategic use of the personal pronoun 'we'. Journal of Language and Politics, 12(3), 315-334.

Nunberg, G. (1993). Indexicality and deixis. Linguistics and Philosophy, 16, 1-43.

Pennycook, A. (1994). The politics of pronouns. ELT Journal, 48(2), 173-178.

Postoutenko, K. (2009). Between 'I' and 'we': Studying the grammar of social identity in Europe (1900-1950). Journal of Language and Politics, 8(2), 195-222.

Prandi, M. (2004). The Building Blocks of Meaning. Amsterdam/Philadelphia: John Benjamins.

Prieto, L. J. (1977). Una nota de gramatica : 'Nosotros' plural de ‘yo'?. In Estudios ofrecidos a Emilio Alarcos Llorach (pp. 209-216). Oviedo: Universidad de Oviedo.

Quirk, R., Greenbaum, S., Leech, G., \& Svartvik, J. (1985). Comprehensive Grammar of the English Language. London: Longman.

Robinson, D. (2017). Benveniste and the periperformative structure of the pragmeme. In K. Allan, et al. (Eds.), Pragmemes and Theories of Language Use. Switzerland: Springer.

Roitman, M. (2014). Presidential candidates' ethos of credibility: The case of the presidential pronoun I in the 2012 Hollande-Sarkozy debate. Discourse and Society, 25(6), 741-765.

Sarlin, P. (2017). Between We and Me: Filmed Interviews and the Politics of Personal Pronouns. Discourse, 39(3), 319-337. 
Siewierska, A. (2004). Person. Cambridge: Cambridge University Press.

Silverstein, M. (1976). Shifters, linguistic categories, and cultural description. In K. Basso, \& H. Selby (Eds.), Meaning in Anthropology (pp. 11-55). Albuquerque, NM: University of New Mexico Press.

Silverstein, M. (2003). Indexical order and the dialectics of sociolinguistic life. Language \& Communication, 23, 193-229.

Simon-Vandenbergen, A. M., Taverniers, M., \& Ravelli, L. (2003). Grammatical Metaphor. Views from Systemic Functional Linguistics. Amsterdam/Philadelphia: John Benjamins.

Skorczynska, H. (2020). “We are prepared to play our part...": A case study of the use of first-person references in e-releases from two oil companies. Journal of Pragmatics, 155, $1-14$.

Urban, G. (1986). Rhetoric of a war chief. Working Papers and Proceedings of the Centre for Psychosocial Studies, Chicago, 5, 1-27.

Van Dijk, T. (1991). Racism in the Press: Critical Studies in Racism and Migration. London: Routledge.

Weinrich, H. (1963). Semantik der kühnen Metapher. Deutsche Vierteljahrsschrift für Literaturwissenschaft und Geistesgeschichte, 37, 325-344.

White, G. B. (2017). First-Person Pronoun Use in English Editorials from Taiwan Newspapers. Taiwan International ESP Journal, 12(1), 1-20.

Wilson, J. (1990). Politically Speaking. Oxford: Basil Blackwell.

Wilson, N. (2019). When we means you. The social meaning of English pseudo-inclusive personal pronouns. In P. Bouissac (Ed.), The Social Dynamics of Pronominal Systems. A Comparative Approach (pp. 35-56). Amsterdam/Philadelphia: John Benjamins.

Wodak, R. (1997). Das Ausland and anti-semitic discourse: The discursive construction of the other. In S. H. Higgins (Ed.), The Language and Politics of Exclusion: Others in Discourse (pp. 65-87). London: Sage.

Wodak, R. (Ed.) (1989). Language, Power and Ideology: Studies in Political Discourse. Amsterdam/Philadelphia: John Benjamins.

Yang, W. (2017). Audioslide Presentations as an Appendant Genre. Key Words, Personal Pronouns, Stance and Engagement. ESP Today, 5(1), 24-45.

Yu, H., \& Wu, C. (2017). Recreating the image of Chan master Huineng. Target. International Journal of Translation Studies, 29(1), 64-86.

Zupnik, Y. J. (1994). A pragmatic analysis of the use of person deixis in political discourse. Journal of Pragmatics, 21(4), 339-383. 


\section{Notes}

Note 1. I am grateful to Nathan Salmon for this suggestion, given during a workshop in Messina (July 2019).

Note 2. The actual quotation spells: "That's one small step for a man, a giant leap for mankind".

Note 3. In recent years, the oppositions singled out by Benveniste have been re-examined and discussed in the light of the evolution of pragmatic research, in particular with reference to the concept of periperformativity (Robinson 2017).

Note 4. In more recent literature, this is also called pluralis modestiae, as it reduces the dominance of I, indicating joint rather than single authorship (Siewierska 2004).

Note 5. I consulted the following dictionaries: OED on-line (https://www.oed.com/), Merriam-Webster on-line (https://www.merriam-webster.com/), Collins on-line (https://www.collinsdictionary.com/) [last accessed July 30th 2019].

Note 6. A special issue of Pragmatics (26/2016) was also dedicated to special uses of personal pronouns. The first person plural, though mentioned in the introduction (De Cock/Kluge, 2016) is treated only in one paper, authored by one of the editors (De Cock, 2016).

Note 7. A corpus-based approach, integrating quantitative and qualitative analysis, is adopted by Wilson (2019), in a paper focused on pseudo-inclusive we as a means to enhance solidarity and mitigate leadership in the discourse of rugby team coaches.

Note 8. https://www.merriam-webster.com/dictionary/we [last accessed 7.10.2019].

Note 9. The translation of the Italian examples is strictly literal.

Note 10. Obviously, the interpersonal metafunction is also involved, as the pronominal system typically realizes it.

Note 11. The full text of the speech can be read on the Winston Churchill website (https://winstonchurchill.org/resources/speeches/1940-the-finest-hour/we-shall-fight-on-the-b eaches/)

Note 12. Incidentally, Wilson explains the doctor-we "in Gricean terms, in that the well-being of the speaker (doctor) in this situation has limited relevance compared to the well-being of the patient", thus hinting at the (flouted) Maxim of Relation, with a consequent conversational implicature (Wilson, 1990: 49).

\section{Copyrights}

Copyright for this article is retained by the author(s), with first publication rights granted to the journal.

This is an open-access article distributed under the terms and conditions of the Creative Commons Attribution license (http://creativecommons.org/licenses/by/4.0/) 